\title{
Antibiotic use in children and youths with asthma: a population-based case-control study
}

\author{
Ivy Fong ${ }^{1}$, Jingqin Zhu $^{1,2}$, Yaron Finkelstein ${ }^{1,2,3,4}$ and Teresa To ${ }^{1,2,5}$
}

Affiliations: ${ }^{1}$ Child Health Evaluative Sciences, The Hospital for Sick Children, Toronto, ON, Canada. ${ }^{2}$ ICES, Toronto, ON, Canada. ${ }^{3}$ Division of Emergency Medicine, The Hospital for Sick Children, Toronto, ON, Canada. ${ }^{4}$ Paediatrics, Pharmacology and Toxicology, University of Toronto, Toronto, ON, Canada. ${ }^{5}$ Dalla Lana School of Public Health, University of Toronto, Toronto, ON, Canada.

Correspondence: Teresa To, Child Health Evaluative Sciences, Peter Gilgan Centre for Research and Learning, The Hospital for Sick Children, 686 Bay St, Toronto ON, M5G 0A4, Canada.

E-mail: teresa.todsickkids.ca

\section{ABSTRACT}

Rationale: Antibiotics are among the most common medications dispensed to children and youths. The objective of this study was to characterise and compare antibiotic use patterns between children and youths with and without asthma.

Methods: We conducted a population-based nested case-control study using health administrative data from Ontario, Canada, in 2018. All Ontario residents aged 5-24 years with asthma were included as cases. Cases were matched to controls with a 1:1 ratio based on age (within 0.5 year), sex and location of residence. Multivariable conditional logistic regression was used to obtain an odds ratio and $95 \%$ confidence interval for having filled at least one antibiotic prescription, adjusted for socioeconomic status, rurality, and presence of common infections, allergic conditions and complex chronic conditions.

Results: The study population included 1174424 Ontario children and youths aged 5-24 years. 31\% of individuals with asthma and $23 \%$ of individuals without asthma filled at least one antibiotic prescription. The odds of having filled at least one antibiotic prescription were $34 \%$ higher among individuals with asthma compared to those without asthma (OR 1.34, 95\% CI 1.32-1.35). In the stratified analysis, the odds ratios were highest in the youngest group of children studied, aged 5-9 years (OR 1.45, 95\% CI 1.41-1.48), and in females (OR 1.36, 95\% CI 1.34-1.38).

Conclusion: Asthma is significantly associated with increased antibiotic use in children and youths. This association is the strongest in younger children and in females.

@ERSpublications

Asthma is significantly associated with increased antibiotic use in children and youths. The odds of antibiotic use are $34 \%$ higher in individuals with asthma. This association is the strongest in younger children and in females. https://bit.ly/3dusuz 9

Cite this article as: Fong I, Zhu J, Finkelstein YAntibiotic use in children and youths with asthma: a population-based case-control study. ERJ Open Res 2021; 7: 00944-2020 [https://doi.org/10.1183/ 23120541.00944-2020].

This article has supplementary material available from openres.ersjournals.com

Received: 16 Dec 2020 | Accepted: 14 Feb 2021

Copyright $\odot$ The authors 2021. This version is distributed under the terms of the Creative Commons Attribution NonCommercial Licence 4.0. For commercial reproduction rights and permissions contact permissions@ersnet.org 


\section{Introduction}

Antibiotics are among the most common medications dispensed to children and youths [1, 2]. It is estimated that first-line antibiotics contributed to saving $\geqslant 17000$ lives in Canada in 2018 [3]. The prevalence of antibiotic prescriptions among children and youths has decreased in recent years $[1,2,4]$. However, there has been increasing concern about unwarranted antibiotic prescribing and increased antibiotic resistance, and subsequent calls by authorities for more research and investment in resources to reverse these trends $[3,5]$. This study aimed to address this need by characterising antibiotic use patterns among children and youths with asthma.

Asthma affects 2339 million individuals worldwide [6]. It is the most common chronic condition in childhood [6], affecting one in eight children [7]. Examining antibiotic use among children and youths with asthma is important due to the high prevalence of asthma, and because antibiotic use may lead to increased healthcare costs and adverse drug events such as allergic reactions, neurotoxic effects and infection with antibiotic-resistant organisms $[8,9]$. The use of multiple drugs (i.e. polypharmacy) has been identified as an important predictor of adverse drug events in children [10]. Children with asthma could potentially be at greater risk of experiencing adverse drug events because they may use multiple drugs, including inhaled corticosteroids and antibiotics [11].

A recent retrospective cohort study using a discordant twin design reported that children exposed to antibiotic use in early life may be at increased risk of developing asthma [12]. Previous studies on early-life antibiotic exposure and later asthma development have been criticised for study limitations such as poor data collection methods and small sample size, and researchers have suggested that fure studies should examine the number of antibiotics used in early life $[12,13]$. In the existing literature on antibiotic use among children and youths with asthma, few studies have used comprehensive population-based data. Previous studies that included only individuals enrolled in participating primary care practices [14] or health plans [15] may be subject to selection bias and their results may not be representative of the general population of children and youths. Thus, the objective of this study was to use population-based data to characterise and compare antibiotic use patterns between children and youths with and without asthma. This was examined in a population of 1174424 individuals aged 5-24 years from Ontario, Canada.

\section{Methods}

\section{Study design}

To characterise and compare antibiotic use patterns between children and youths with and without asthma, we conducted a population-based nested case-control study from 1 January 2018 to 31 December 2018 using health administrative data from Ontario, Canada. The study population included Ontario children and youths aged 5-24 years.

\section{Study population}

Individuals with a physician diagnosis of asthma were identified using a validated health administrative definition of at least one hospitalisation for asthma or at least two outpatient visits for asthma in two consecutive years. This case definition has been validated [16] and used in previous studies [17-19]. All Ontario residents aged 5-24 years with asthma were included as cases in this study. Asthma cases were matched to nonasthma controls with a $1: 1$ ratio based on age (within 0.5 year), sex and location of residence as defined by local health integration networks (LHINs). LHINs are geographical regions established across Ontario to plan, fund and coordinate local community-based health services [20]. Individuals were excluded from the study if they were ever diagnosed with diabetes, cancer or COPD, or if they ever had an organ transplant. Individuals were also excluded if they did not have a valid Ontario health card number or Ontario residence code, or if they had missing data on covariates.

\section{Data sources}

This population-based study used Ontario health administrative data linked using unique coded identifiers at ICES (formerly the Institute for Clinical Evaluative Sciences) in Toronto, Ontario. Health administrative data are routinely collected through Ontario's publicly funded healthcare system. During the 2018 study period, free public prescription drug coverage was available to all Ontario residents aged 0-24 years through the Ontario Health Insurance Plan Plus (OHIP+) programme [21]. The OHIP+ programme covered the full cost of $>4400$ drugs, including almost all oral antibiotics [21]. With the OHIP+ programme, the prescription drug claims of the study population during the study period were captured in provincial health administrative data.

Health administrative databases used in this study included the Registered Persons Database (sociodemographic information), Discharge Abstract Database (hospital admissions), National Ambulatory Care Reporting System (emergency department visits), Ontario Health Insurance Plan Claims Database 
(outpatient physician visit claims), Ontario Drug Benefit Claims Database (prescriptions filled), Ontario Asthma Surveillance Information System (asthma), Ontario Diabetes Database (diabetes), Ontario Cancer Registry (cancer) and Chronic Obstructive Pulmonary Disease Database (COPD).

\section{Outcome definition}

The primary outcome of antibiotic use was defined as a binary variable by whether an individual filled at least one antibiotic prescription. All antibiotics eligible for coverage through the OHIP+ programme were included. Additionally, the use of antibiotic classes commonly prescribed for bacterial respiratory infections, i.e. cephalosporins, macrolides and penicillins, were examined combined as one secondary outcome and separately by class.

\section{Covariates}

Socioeconomic status was measured using the Ontario Marginalization Index. The Ontario Marginalization Index uses census data to measure four dimensions of marginalisation (material deprivation, dependency, ethnic concentration and residential instability) at the neighbourhood level [22]. Individuals are assigned a value from 1 (least marginalised) to 5 (most marginalised) for each dimension based on their residence neighbourhood [22]. Residence was defined as rural if an individual resided in a community of $\leqslant 10000$ people [20]. Otherwise, residence was defined as urban [20]. The presence of common infections and allergic conditions, including bronchitis, influenza, pneumonia, allergic rhinitis, eczema, tonsillitis, adenoiditis, ear infection and appendicitis [23-25], was defined as any health service claim for these conditions identified using International Classification of Diseases, 10th Revision (ICD-10), Ontario Health Insurance Plan and Canadian Classification of Health Interventions codes (table S1). The presence of complex chronic conditions, as described previously [26], was defined as any hospitalisation for these conditions identified using ICD-10 codes (table S2).

\section{Statistical analysis}

Baseline characteristics of the study population were described with the frequency and proportion of categorical variables, and the mean and standard deviation of continuous variables. Antibiotic use was described with the frequency and proportion of individuals who filled at least one prescription for each antibiotic category, and stratified by age and sex subgroups. Differences in baseline characteristics and antibiotic use between asthma cases and nonasthma controls were compared using standardised difference scores to provide a statistical measure of differences between groups that is not influenced by the large sample size [27, 28].

Multivariable conditional logistic regression was used to obtain an adjusted odds ratio and $95 \%$ confidence interval for having filled at least one antibiotic prescription, comparing asthma cases and nonasthma controls. Cases were matched to controls on age (within 0.5 year), sex and location of residence, and the remaining unmatched variables of socioeconomic status, rurality, and presence of common infections, allergic conditions and complex chronic conditions were included in the model. The definitions of these variables are outlined in the Covariates section. The model was repeated for each antibiotic category, and stratified by age and sex subgroups. A p-value of $<0.05$ was used to determine statistical significance. All analyses were carried out using SAS 9.4 (SAS Institute Inc., Cary, NC, USA).

\section{Research ethics}

Ethics approval was obtained from the Hospital for Sick Children Research Ethics Board in Toronto, Ontario. Individual consent was not required as only deidentified provincial health administrative data were used in this study.

\section{Results}

Characteristics of the study population

The study population included 1174424 Ontario children and youths aged 5-24 years. Most were male (58.5\%) and the largest age group was adolescents aged 15-19 years (29.2\%) (table 1). Among individuals with asthma, the mean \pm SD asthma duration was $11.6 \pm 6.0$ years. Asthma cases and nonasthma controls were distributed equally across the Ontario Marginalization Index dimensions. Most asthma cases (92.9\%) and nonasthma controls (91.8\%) lived in urban areas. A higher proportion of individuals with asthma had bronchitis (5.2\%) and allergic rhinitis (5.2\%) compared to individuals without asthma (3.0\% and $3.0 \%$, respectively). The characteristics of the study population by type of antibiotic received are presented in the supplementary material (table S3).

\section{Antibiotic use}

A larger proportion of individuals with asthma filled at least one antibiotic prescription; $30.6 \%$ of asthma cases compared to $23.1 \%$ of nonasthma controls (table 2). Similarly, $26.4 \%$ of asthma cases and $19.5 \%$ of 


\begin{tabular}{|c|c|c|c|}
\hline Characteristic & Asthma cases ${ }^{\#}$ & Nonasthma controls" & Standardised difference ${ }^{\pi}$ \\
\hline \multicolumn{4}{|l|}{ Age group at baseline years } \\
\hline $5-9$ & $115189(19.6 \%)$ & $115189(19.6 \%)$ & 0.000 \\
\hline $10-14$ & $147737(25.2 \%)$ & $147737(25.2 \%)$ & 0.000 \\
\hline $15-19$ & $171356(29.2 \%)$ & $171356(29.2 \%)$ & 0.000 \\
\hline $20-24$ & $152930(26.0 \%)$ & $152930(26.0 \%)$ & 0.000 \\
\hline \multicolumn{4}{|l|}{ Sex } \\
\hline Female & $243969(41.5 \%)$ & $243969(41.5 \%)$ & 0.000 \\
\hline Male & $343243(58.5 \%)$ & $343243(58.5 \%)$ & 0.000 \\
\hline Asthma duration years mean \pm sD & $11.6 \pm 6.0$ & & \\
\hline \multicolumn{4}{|l|}{ Ontario Marginalization Index } \\
\hline \multicolumn{4}{|l|}{ Deprivation quintile } \\
\hline 1 , lowest & $133636(22.8 \%)$ & $131345(22.4 \%)$ & 0.009 \\
\hline 2 & $128432(21.9 \%)$ & $126630(21.6 \%)$ & 0.007 \\
\hline 3 & $111763(19.0 \%)$ & $111344(19.0 \%)$ & 0.002 \\
\hline 4 & $101696(17.3 \%)$ & $103949(17.7 \%)$ & 0.010 \\
\hline 5 , highest & $111685(19.0 \%)$ & $113944(19.4 \%)$ & 0.010 \\
\hline \multicolumn{4}{|l|}{ Dependency quintile } \\
\hline 1 , lowest & $194920(33.2 \%)$ & $192883(32.8 \%)$ & 0.007 \\
\hline 2 & $129077(22.0 \%)$ & $128180(21.8 \%)$ & 0.004 \\
\hline 3 & $100243(17.1 \%)$ & $100692(17.1 \%)$ & 0.002 \\
\hline 4 & $88636(15.1 \%)$ & $89773(15.3 \%)$ & 0.005 \\
\hline 5, highest & $74336(12.7 \%)$ & $75684(12.9 \%)$ & 0.007 \\
\hline \multicolumn{4}{|l|}{ Ethnic Concentration Quintile } \\
\hline 1, lowest & $66831(11.4 \%)$ & $68204(11.6 \%)$ & 0.007 \\
\hline 2 & $83814(14.3 \%)$ & $81572(13.9 \%)$ & 0.011 \\
\hline 3 & $101785(17.3 \%)$ & $97088(16.5 \%)$ & 0.021 \\
\hline 4 & $132846(22.6 \%)$ & $127439(21.7 \%)$ & 0.022 \\
\hline 5 , highest & $201936(34.4 \%)$ & 212909 (36.3\%) & 0.039 \\
\hline \multicolumn{4}{|l|}{ Residential Instability Quintile } \\
\hline 1, lowest & $172074(29.3 \%)$ & $162727(27.7 \%)$ & 0.035 \\
\hline 2 & $117815(20.1 \%)$ & $115345(19.6 \%)$ & 0.011 \\
\hline 3 & $101220(17.2 \%)$ & $101141(17.2 \%)$ & 0.000 \\
\hline 4 & $98530(16.8 \%)$ & $97822(16.7 \%)$ & 0.003 \\
\hline 5, highest & $97573(16.6 \%)$ & $110177(18.8 \%)$ & 0.056 \\
\hline \multicolumn{4}{|l|}{ Rurality } \\
\hline Urban & $545302(92.9 \%)$ & $539000(91.8 \%)$ & 0.040 \\
\hline Rural & $41910(7.1 \%)$ & $48212(8.2 \%)$ & 0.040 \\
\hline \multicolumn{4}{|l|}{$\begin{array}{l}\text { Presence of common infections } \\
\text { and allergic conditions }\end{array}$} \\
\hline Bronchitis & $30447(5.2 \%)$ & $17859(3.0 \%)$ & 0.108 \\
\hline Influenza & $8217(1.4 \%)$ & $5835(1.0 \%)$ & 0.037 \\
\hline Pneumonia & $8564(1.5 \%)$ & $4542(0.8 \%)$ & 0.065 \\
\hline Allergic rhinitis & $30684(5.2 \%)$ & $17525(3.0 \%)$ & 0.113 \\
\hline Eczema & $41825(7.1 \%)$ & $30477(5.2 \%)$ & 0.080 \\
\hline Tonsillitis and adenoiditis & $21561(3.7 \%)$ & $15831(2.7 \%)$ & 0.056 \\
\hline Ear infection & $39570(6.7 \%)$ & $28824(4.9 \%)$ & 0.078 \\
\hline Appendicitis & $1837(0.3 \%)$ & $1482(0.3 \%)$ & 0.011 \\
\hline \multicolumn{4}{|l|}{$\begin{array}{l}\text { Presence of any complex chronic } \\
\text { condition }\end{array}$} \\
\hline Yes & $1465(0.2 \%)$ & $924(0.2 \%)$ & 0.020 \\
\hline No & $585747(99.8 \%)$ & $586288(99.8 \%)$ & 0.020 \\
\hline
\end{tabular}

nonasthma controls filled at least one antibiotic prescription commonly prescribed for respiratory infections. The same pattern was observed across all age and sex subgroups for each antibiotic category.

Among individuals with asthma, antibiotic use did not differ by asthma duration but was higher among those with more recently diagnosed asthma (table S4). A similar pattern was observed for antibiotics commonly prescribed for respiratory infections and penicillins. There was no statistical difference in cephalosporin and macrolide use by asthma duration. 
TABLE 2 Number of individuals who filled at least one antibiotic prescription by asthma diagnosis, age group and sex ( $N=1$ 174424)

\begin{tabular}{|c|c|c|c|}
\hline \multirow[t]{2}{*}{ Antibiotic prescriptions by age group and sex } & \multicolumn{2}{|c|}{ Individuals that filled $\geqslant 1$ antibiotic prescription } & \multirow{2}{*}{$\begin{array}{l}\text { Standardised } \\
\text { difference }\end{array}$} \\
\hline & Asthma cases ${ }^{\#}$ & Nonasthma controls ${ }^{\#}$ & \\
\hline \multicolumn{4}{|l|}{ All antibiotics } \\
\hline $5-9$ years old & $43675(37.9 \%)$ & $31216(27.1 \%)$ & 0.232 \\
\hline $10-14$ years old & $39210(26.5 \%)$ & $27949(18.9 \%)$ & 0.183 \\
\hline $15-19$ years old & $53901(31.5 \%)$ & $41876(24.4 \%)$ & 0.157 \\
\hline Male & $95619(27.9 \%)$ & $72171(21.0 \%)$ & 0.159 \\
\hline \multicolumn{4}{|c|}{ Antibiotics commonly prescribed for respiratory infections } \\
\hline All & $155210(26.4 \%)$ & $114540(19.5 \%)$ & 0.165 \\
\hline $5-9$ years old & $40947(35.5 \%)$ & $28939(25.1 \%)$ & 0.228 \\
\hline $10-14$ years old & $34492(23.3 \%)$ & $23967(16.2 \%)$ & 0.180 \\
\hline $15-19$ years old & $44706(26.1 \%)$ & $33841(19.7 \%)$ & 0.151 \\
\hline \multicolumn{4}{|l|}{ Cephalosporins } \\
\hline All & $14234(2.4 \%)$ & 9147 (1.6\%) & 0.062 \\
\hline 5-9 years old & $4856(4.2 \%)$ & $2992(2.6 \%)$ & 0.089 \\
\hline $10-14$ years old & $3339(2.3 \%)$ & $2010(1.4 \%)$ & 0.068 \\
\hline $15-19$ years old & $3388(2.0 \%)$ & 2276 (1.3\%) & 0.051 \\
\hline $20-24$ years old & $2651(1.7 \%)$ & 1869 (1.2\%) & 0.042 \\
\hline Female & 6759 (2.8\%) & $4420(1.8 \%)$ & 0.064 \\
\hline Male & $7475(2.2 \%)$ & $4727(1.4 \%)$ & 0.061 \\
\hline \multicolumn{4}{|l|}{ Macrolides } \\
\hline All & $54382(9.3 \%)$ & 34654 (5.9\%) & 0.127 \\
\hline 5-9 years old & $11665(10.1 \%)$ & $6820(5.9 \%)$ & 0.155 \\
\hline $10-14$ years old & $12243(8.3 \%)$ & $7207(4.9 \%)$ & 0.138 \\
\hline $15-19$ years old & $16390(9.6 \%)$ & $10687(6.2 \%)$ & 0.124 \\
\hline 20-24 years old & 14084 (9.2\%) & 9940 (6.5\%) & 0.101 \\
\hline Female & 52033 (21.3\%) & $40063(16.4 \%)$ & 0.126 \\
\hline Male & 57889 (16.9\%) & $44645(13.0 \%)$ & 0.109 \\
\hline
\end{tabular}

Adjusted odds of having filled at least one antibiotic prescription

In the multivariable conditional logistic regression analysis, the adjusted odds of having filled at least one antibiotic prescription were $34 \%$ higher among children and youths with asthma compared to individuals without asthma (OR 1.34, 95\% CI 1.32-1.35) (table 3). Similarly, the odds of having filled at least one antibiotic prescription commonly prescribed for respiratory infections were $35 \%$ higher among children and youth with asthma compared to individuals without asthma (OR 1.35, 95\% CI 1.33-1.36). The odds were also higher among individuals with asthma across all age and sex subgroups for each antibiotic category (figures 1 and 2). The unadjusted and adjusted odds ratios for the age and sex subgroups are presented in the supplementary material (table S5).

In the age-stratified analysis, the odds of having filled at least one antibiotic prescription were highest in the youngest group of children studied, aged 5-9 years (OR 1.45, 95\% CI 1.41-1.48) (figure 1). The odds ratios decreased in a stepwise fashion with increasing age. Similarly, the odds of having filled at least one antibiotic prescription commonly prescribed for respiratory infections were also highest in children aged 


\begin{tabular}{|c|c|c|c|c|}
\hline \multirow[t]{2}{*}{ Antibiotic prescriptions } & \multicolumn{2}{|c|}{ Unadjusted } & \multicolumn{2}{|c|}{ Adjusted } \\
\hline & OR $(95 \% \mathrm{CI})$ & p-value ${ }^{\#}$ & OR $(95 \% \mathrm{CI})$ & p-value \\
\hline All antibiotics & $1.48(1.47-1.49)$ & $<0.0001$ & $1.34(1.32-1.35)$ & $<0.0001$ \\
\hline $\begin{array}{l}\text { Antibiotics commonly prescribed for } \\
\text { respiratory infections }\end{array}$ & $1.50(1.48-1.51)$ & $<0.0001$ & $1.35(1.33-1.36)$ & $<0.0001$ \\
\hline Cephalosporins & $1.57(1.53-1.62)$ & $<0.0001$ & $1.37(1.33-1.41)$ & $<0.0001$ \\
\hline Macrolides & $1.63(1.61-1.65)$ & $<0.0001$ & $1.46(1.43-1.48)$ & $<0.0001$ \\
\hline Penicillins & $1.38(1.36-1.39)$ & $<0.0001$ & $1.25(1.24-1.27)$ & $<0.0001$ \\
\hline
\end{tabular}

5-9 years (OR 1.45, 95\% CI 1.42-1.49). The odds ratios for antibiotic prescriptions commonly prescribed for respiratory infections also decreased in a stepwise fashion with increasing age. The same pattern was observed for penicillins. A similar pattern was observed for cephalosporins and macrolides but for these antibiotic classes, the odds were highest in children aged 10-14 years.

In the sex-stratified analysis, the odds of having filled at least one antibiotic prescription were higher in females (OR 1.36, 95\% CI 1.34-1.38) (figure 2) than males. The odds of having filled at least one antibiotic prescription commonly prescribed for respiratory infections were also higher in females (OR 1.36, 95\% CI 1.34-1.38). The same pattern was observed for penicillins but not for cephalosporins or macrolides.

\section{Discussion}

To our knowledge, this is the largest population-based study to date on antibiotic use in children and youths with and without asthma. We found that $30.6 \%$ of individuals with asthma and $23.1 \%$ of individuals without asthma filled at least one antibiotic prescription. The odds of having filled at least one antibiotic prescription were significantly higher among children and youths with asthma compared to individuals without asthma. In the stratified analysis, we found that the odds were highest in the youngest group of children studied, aged 5-9 years, and in females. A similar pattern was observed for antibiotics commonly prescribed for respiratory infections, including cephalosporins, macrolides and penicillins.

STALLWORTH et al. [15] found that antibiotic use was significantly increased in US children aged 5-18 years with asthma for respiratory, nonrespiratory, bacterial and viral conditions. Similarly, BAAN et al. [29] found that antibiotic use was significantly higher in UK and Dutch children aged 5-18 years with asthma. The authors also found that one in seven children with asthma received antibiotics during asthma exacerbation. Healthcare providers may prescribe antibiotics during asthma exacerbation to treat or prevent potential secondary respiratory infections and because the anti-inflammatory effects of antibiotics, particularly macrolides, may be useful for controlling inflammation in individuals with asthma [30, 31]. However, antibiotic use is associated with increased risk of dysbiosis in the airway, which may lead to increased inflammation [32].

We found that asthma was significantly associated with increased odds of use of antibiotics commonly prescribed for respiratory infections in children and youths. HAK et al. [14] found that antibiotic prescriptions were higher in children with asthma aged 2-12 years because upper respiratory tract infections such as rhinitis, sinusitis and laryngitis were more common in these children. Similarly, BAAN et al. [29] found that antibiotics were prescribed more often to children with asthma for lower respiratory tract infections, such as pneumonia. The authors suggested that children with asthma may receive more antibiotic prescriptions because it may be particularly challenging to distinguish between bacterial and viral lower respiratory tract infections in children with asthma [29].

In the age-stratified analysis, we found that the association between asthma and antibiotic use was the strongest in the youngest group of children studied, aged 5-9 years. Among Belgian children aged 0-18 years, De BOECK et al. [33] found that antibiotic prescriptions decreased with age. In a study of antibiotic use in Northern Italy, FRANCHI et al. [34] also found that antibiotics prescribed to children decreased with age toward adolescence. Higher antibiotic use may be attributable to the increased frequency of infections among younger children [35]. 


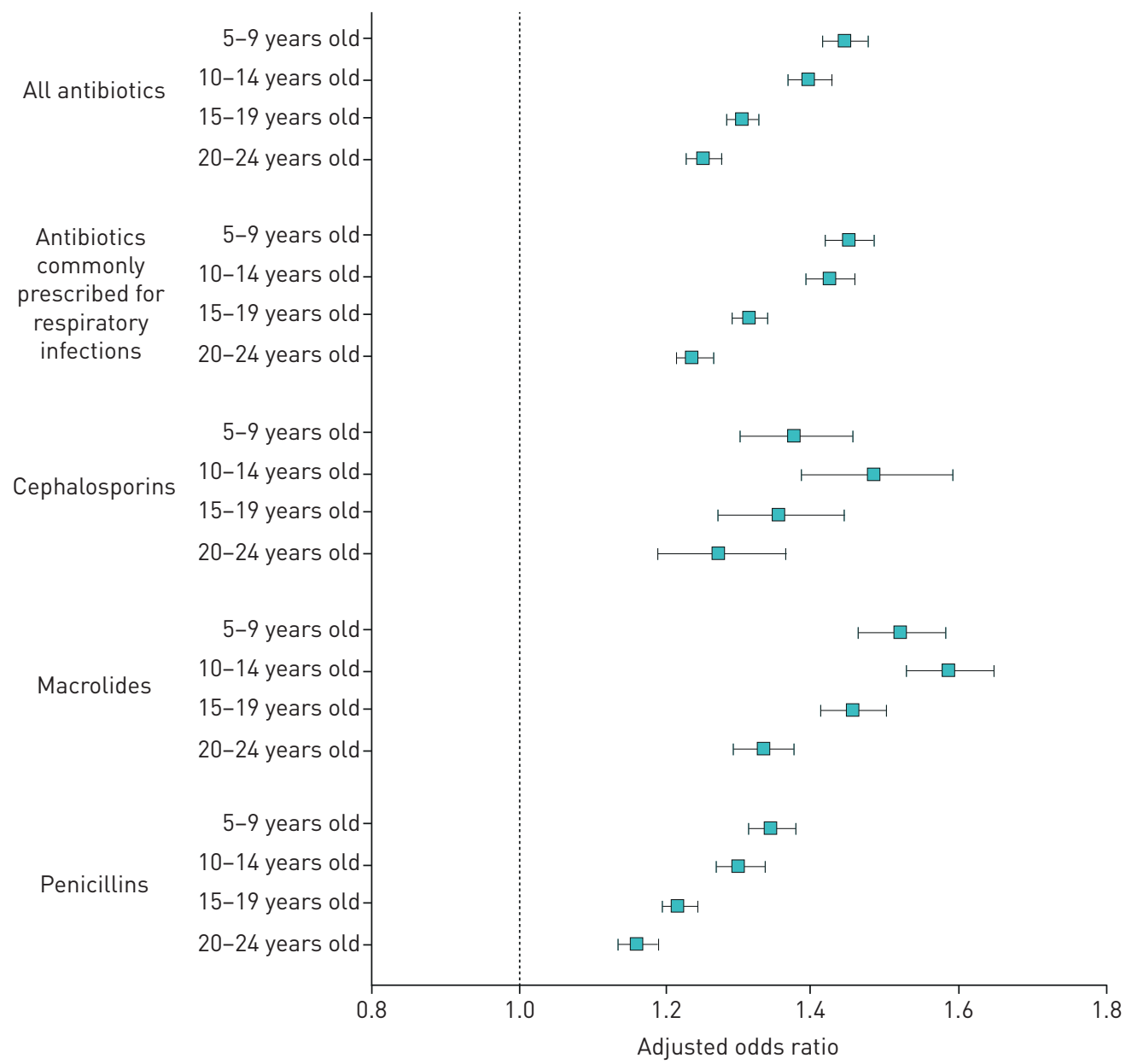

FIGURE 1 Adjusted odds of having filled at least one antibiotic prescription for children and youths with asthma versus without asthma from conditional logistic regression by age group ( $N=1174424)$. The conditional logistic regression models were adjusted for Ontario Marginalization Index, rurality, bronchitis, influenza, pneumonia, allergic rhinitis, eczema, tonsillitis, adenoiditis, ear infection, appendicitis and complex chronic conditions.

In the sex-stratified analysis, we found that the association between asthma and antibiotic use was stronger in females than males. Similarly, STALLWORTH et al. [15] found that antibiotic use was higher among females with asthma. Previous research has demonstrated that young girls with asthma may experience less asthma symptoms, such as wheezing, compared to boys [15, 36]. This may lead to less aggressive treatment of asthma with inhaled corticosteroids, which could lead to a greater risk of secondary infections requiring antibiotic therapy in young girls [15]. Additionally, because of their anatomy, females are more susceptible to infections such as urinary tract infections and pelvic inflammatory disease, which may lead to increased antibiotic use compared to males $[37,38]$.

Antibiotic use was observed in nearly one in three individuals with asthma and one in four individuals without asthma. Exposure to antibiotic use in early life, especially antibiotics prescribed for respiratory infections, may lead to increased risk of asthma [12]. As such, physicians should consider the potential risks and benefits of antibiotics prescriptions for young children [12]. The higher odds of antibiotic use observed in children and youths with asthma may be a result of antibiotic prescriptions for asthma exacerbation [29], and the higher risk of infections among individuals with asthma [14, 29, 39], younger children [35] and females [15]. Researchers, physicians and policy-makers should identify and implement novel strategies, and strengthen existing strategies to prevent asthma exacerbations and minimise infections that lead to antibiotic use in children and youths with asthma (e.g. strengthen existing strategies to limit exposure to asthma triggers such as tobacco smoke through legislation, promote influenza vaccination, provide education on preventing common infections such as urinary tract infections, and increase adherence to inhaled corticosteroid maintenance treatment in children with asthma).

In this study, health administrative data was used to collect information about antibiotic prescriptions filled by children and youths in Ontario. The use of health administrative data limited our ability to 


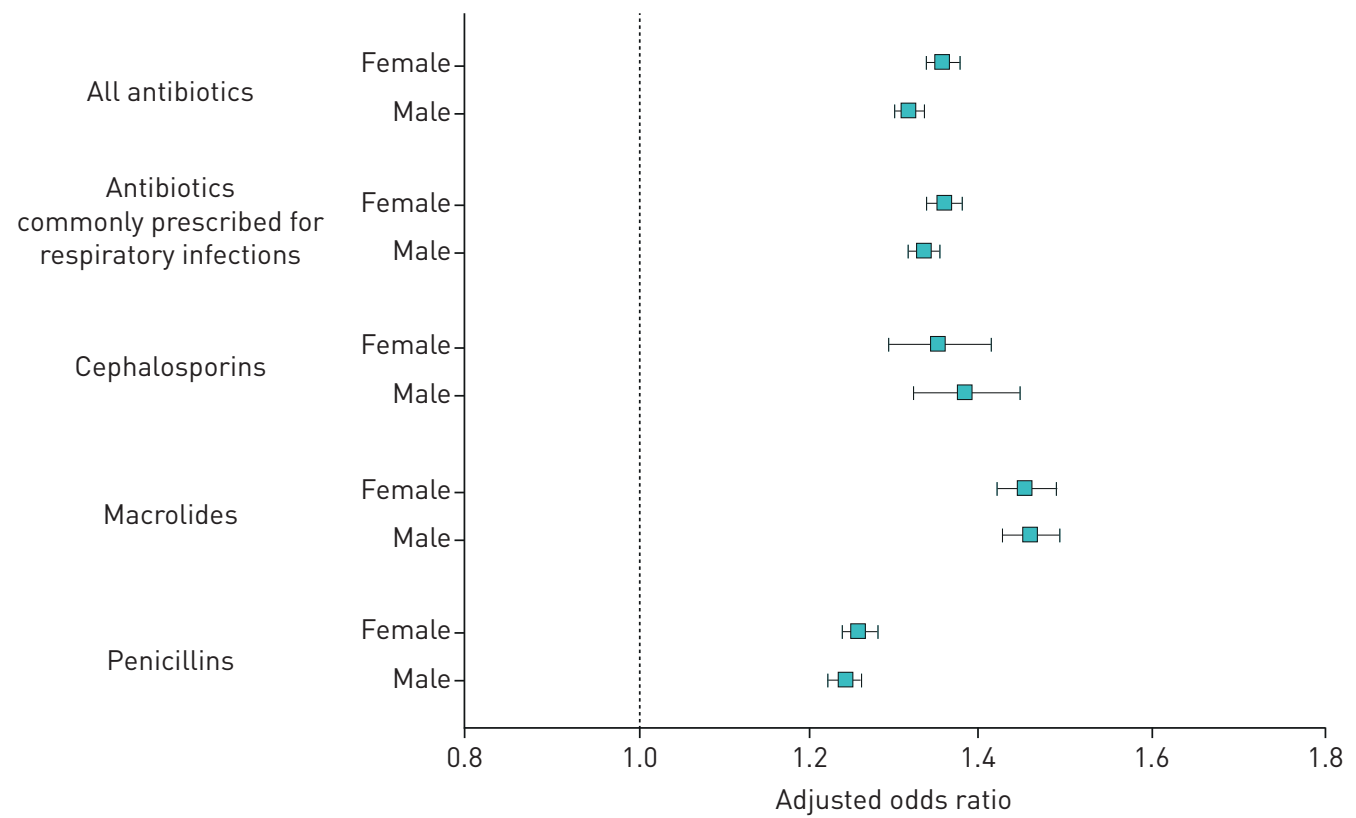

FIGURE 2 Adjusted odds of having filled at least one antibiotic prescription for children and youths with asthma versus without asthma from conditional logistic regression by sex $(N=1174424)$. The conditional logistic regression models were adjusted for Ontario Marginalization Index, rurality, bronchitis, influenza, pneumonia, allergic rhinitis, eczema, tonsillitis, adenoiditis, ear infection, appendicitis and complex chronic conditions.

examine potentially relevant variables such as ethnicity, asthma severity and parental allergy. Our ability to examine the indications for which antibiotics were prescribed was also limited. Some children may have been prescribed antibiotics for respiratory viral conditions, which do not require antibiotics. This data source allowed us to study medication use without selection or response bias in a large population, which may allow us to generalise our results to populations in other jurisdictions. Notably, since public drug coverage was available to all Ontario residents aged 0-24 years during the study period, a strength of this study is that antibiotic use was not affected by socioeconomic status, the ability to pay for prescriptions or health insurance coverage.

Future research should examine the relationship between asthma severity and antibiotic use, as well as the dose-response relationship between asthma and antibiotic use. Future research should also examine the association between use of inhaled corticosteroids, $\beta_{2}$-agonists and antibiotics among individuals with asthma.

\section{Conclusion}

In this population-based study, the largest on this topic to date, we found that asthma is significantly associated with increased odds of antibiotic use in children and youths. This association is strongest in younger children and in females. Researchers, physicians and policy-makers should identify and implement novel strategies, and strengthen existing strategies to prevent asthma exacerbations and minimise infections that lead to antibiotic use in children and youths with asthma.

Conflict of interest: None declared.

Support statement: This study was funded by the Ontario Ministry of Health and Long-Term Care (MOHLTC). T. To holds a Canadian Institutes of Health Research Tier 1 Canada Research Chair in Asthma. Data were provided by ICES (formerly the Institute for Clinical Evaluative Sciences), which is funded by an annual grant from the MOHLTC. Parts of this material are based on data and information compiled and provided by the Canadian Institute for Health Information and Cancer Care Ontario. We thank IMS Brogan Inc. for use of their Drug Information Database. The analyses, conclusions, opinions, and statements expressed in this material are those of the authors, and not necessarily those of the funding or data sources; no endorsement is intended or should be inferred. Funding information for this article has been deposited with the Crossref Funder Registry.

\section{References}

1 Hales CM, Kit BK, Gu Q, et al. Trends in prescription medication use among children and adolescents - United States, 1999-2014. JAMA 2018; 319: 2009-2020.

2 Chai G, Governale L, McMahon AW, et al. Trends of outpatient prescription drug utilisation in US children, 2002-2010. Pediatrics 2012; 130: 23-31. 
3 Council of Canadian Academies. When Antibiotics Fail: the Expert Panel on the Potential Socio-Economic Impacts of Antimicrobial Resistance in Canada. Ottawa, Council of Canadian Academies, 2019.

4 King LM, Bartoces M, Fleming-Dutra KE, et al. Changes in US Outpatient Antibiotic Prescriptions from 2011-2016. Clin Infect Dis 2020; 70: 370-377.

5 Public Health Agency of Canada. Handle With Care: Preserving Antibiotics Now and Into the Future. Ottawa, Public Health Agency of Canada, 2019.

6 World Health Organisation. Asthma. 2020. https://www.who.int/news-room/fact-sheets/detail/asthma

7 Statistics Canada. Changes in the prevalence of asthma among Canadian children. 2015. www150.statcan.gc.ca/n1/ pub/82-003-x/2008002/article/10551/5202470-eng.htm

8 Grill MF, Maganti RK. Neurotoxic effects associated with antibiotic use: management considerations. Br J Clin Pharmacol 2011; 72: 381-393.

9 Tamma PD, Avdic E, Li DX, et al. Association of adverse events with antibiotic use in hospitalized patients. JAMA Internal Med 2017; 177: 1308-1315.

10 Smyth RMD, Gargon E, Kirkham J, et al. Adverse drug reactions in children - a systematic review. PLoS One 2012; 7: e24061.

11 Lougheed MD, Lemiere C, Ducharme FM, et al. Canadian Thoracic Society 2012 guideline update: diagnosis and management of asthma in preschoolers, children and adults. Can Respir J 2012; 19: 127-164.

12 Slob EMA, Brew BK, Vijverberg SJH, et al. Early-life antibiotic use and risk of asthma and eczema: Results of a discordant twin study. Eur Respir J 2020; 55: 1902021.

13 Dewan N, Goldman RD. Antibiotic exposure in early life and development of childhood asthma. Can Family Physician 2020; 66: 661.

14 Hak E, Rovers MM, Sachs AP, et al. Is asthma in 2-12 year-old children associated with physician-attended recurrent upper respiratory tract infections? Eur J Epidemiol 2003; 18: 899-902.

15 Stallworth LE, Fick DM, Ownby DR, et al. Antibiotic use in children who have asthma: results of retrospective database analysis. J Managed Care Pharm 2005; 11: 657-662.

16 Gershon AS, Wang C, Guan J, et al. Identifying patients with physician diagnosed asthma in health administrative databases. Can Respir J 2009; 16: 183-188.

17 Gray N, Howard A, Zhu J, et al. Association between inhaled corticosteroid use and bone fracture in children with asthma. JAMA Pediatr 2018; 172: 57-64.

18 Glockler-Lauf SD, Finkelstein Y, Zhu J, et al. Montelukast and neuropsychiatric events in children with asthma: A nested case-control study. J Pediatr 2019; 209: 176-182.

19 To T, Gray N, Ryckman K, et al. Sex differences in health services and medication use among older adults with asthma. ERJ Open Res 2019; 5: 00242-02019.

20 Ontario Ministry of Health and Long-Term Care. Health Analyst's Toolkit. Toronto, Ontario Ministry of Health and Long-Term Care, 2012.

21 Government of Ontario. Learn about OHIP+. 2019. www.ontario.ca/page/learn-about-ohip-plus

22 Matheson FI, van Ingen T. 2011 Ontario Marginalization Index: User guide. Toronto, Public Health Ontario, 2017.

23 Vaz LE, Kleinman KP, Raebel MA, et al. Recent trends in outpatient antibiotic use in children. Pediatrics 2014 133: 375-385.

24 World Allergy Organization. WAO White Book on Allergy. Milwaukee, WAO, 2013.

25 Short HL, Sarda S, Travers C, et al. Trends in common surgical procedures at children's and nonchildren's hospitals between 2000 and 2009. J Pediat Surg 2018; 53: 1472-1477.

26 Feudtner C, Christakis DA, Connell FA. Pediatric deaths attributable to complex chronic conditions: a population-based study of Washington State, 1980-1997. Pediatrics 2000; 106: Suppl. 1, 205

27 Austin PC. Using the standardized difference to compare the prevalence of a binary variable between two groups in observational research. Commun Statist Simul Comput 2009; 38: 1228-1234.

28 Austin PC. Balance diagnostics for comparing the distribution of baseline covariates between treatment groups in propensity-score matched samples. Stat Med 2009; 28: 3083-3107.

29 Baan EJ, Janssens HM, Kerckaert T, et al. Antibiotic use in children with asthma: cohort study in UK and Dutch primary care databases. BMJ open 2018; 8: e022979.

30 Kew KM, Undela K, Kotortsi I, et al. Macrolides for chronic asthma. Cochrane Database Syst Rev 2015; 9: Cd002997.

31 Normansell R, Sayer B, Waterson S, et al. Antibiotics for exacerbations of asthma. Cochrane Database Syst Rev 2018; 6: Cd002741.

32 Chung KF. Airway microbial dysbiosis in asthmatic patients: a target for prevention and treatment? J Allergy Clin Immunol 2017; 139: 1071-1081.

33 De Boeck K, Vermeulen F, Meyts I, et al. Coprescription of antibiotics and asthma drugs in children. Pediatrics 2011; 127: 1022-1026.

34 Franchi C, Sequi M, Bonati M, et al. Differences in outpatient antibiotic prescription in Italy's Lombardy region. Infection 2011; 39: 299.

35 Maltezou HC, Dedoukou X, Asimaki H, et al. Consumption of antibiotics by children in Greece: a cross-sectional study. Int J Pediatr Adolescent Med 2017; 4: 108-111.

36 Almqvist C, Worm M, Leynaert B. Impact of gender on asthma in childhood and adolescence: a GA ${ }^{2}$ LEN review. Allergy 2008; 63: 47-57.

37 Kaufman J, Temple-Smith M, Sanci L. Urinary tract infections in children: an overview of diagnosis and management. BMJ Paediatr Open 2019; 3: e000487-e000487.

38 Curry A, Williams T, Penny ML. Pelvic inflammatory disease: diagnosis, management, and prevention. Am Family Phys 2019; 100: 357-364.

39 Pols DHJ, Nielen MMJ, Bohnen AM, et al. Atopic children and use of prescribed medication: a comprehensive study in general practice. PLoS One 2017; 12: e0182664. 